\title{
Application of diltiazem hydrochloride to hippocampus of juvenile rats with epilepsy and its effects on multidrug-resistance gene expression.
}

\author{
Xing-Xia Li, Yu-Xia Zhang, Jing-Na Wang, Jun-Li Yang* \\ Department of Pediatrics, Qilu Hospital, Shandong University, Ji'nan, PR China
}

\begin{abstract}
Objective: This study aims to investigate the effects of diltiazem hydrochloride (DTZ) on MultidrugResistance (MDR) gene expression.

Methods: Male juvenile rats were randomly divided into two groups: Kainic Acid (KA) group and control group. After the successful establishment of model, juvenile rats in the KA group were randomly divided into three subgroups: EP (Epilepsy untreated with antiepileptic drugs), EP+Lamotrigine (LTG) and EP+LTG+DTZ groups. In addition, rats in the control group were randomly divided into three subgroups: Normal Saline (NS), NS+LTG and NS+LTG+DTZ groups. Rats were given six weeks of LTG and/or DTZ treatment, sacrificed, the hippocampi of rats were obtained, and mdr1a and mdr1b mRNA expression levels were determined by Reverse Transcription-Polymerase Chain Reaction (RT-PCR).

Results: Mdr1a and mdr1b mRNA expression levels were significantly higher in the EP and EP+LTG groups than in the NS group $(\mathbf{P}<\mathbf{0 . 0 1})$, but these levels were not statically significant in the EP+LTG and NS+LTG groups than in the EP and NS groups, respectively $(P>0.05$ and $P>0.05)$. Furthermore, rats in the mdr1a and mdr1b mRNA expression group was lower in the EP+LTG+DTZ group than that in the EP and EP+LTG group $(P<0.05$ and $P<0.05)$, while differences between the NS+LTG+DTZ group with the NS+LTG group and with the NS group were not statistically significant $(P>0.05$ and $P>0.05)$.

Conclusion: Seizures can increase mdr1a and mdr1b mRNA expression in the hippocampus, and LTG had no effect on its expression; while DTZ can reverse the expression trend.
\end{abstract}

Keywords: Multidrug resistance gene, Epilepsy, Calcium Channel blockers, Rat, Hippocampus. Accepted on December 12, 2017

\section{Introduction}

Epilepsy is a common disease of the nervous system, and approximately $25 \%$ of epilepsy patients are resistant to most anti-epileptic drugs and progress into intractable epilepsy [1]. There are a number of evidences that the overexpression of Multidrug-Resistance (MDR) genes play a major role in the pharmacoresistance in epilepsy [2,3]. MDR genes were first discovered by Biedler [1] in the 1980s, among which, $m d r 1$ plays a major role [4]. A study revealed that $m d r l$ in brain tissues of patients with intractable epilepsy appeared to be overexpressed [5]. The enhancement of $m d r 1$ expression prevents antiepileptic drugs to effectively enter the brain cells, which is an important reason for the failure of epilepsy treatment. A study revealed that the overexpression of Pglycoprotein (P-gp) was found in surgically removed brain tissues of epileptic foci in patients with intractable epilepsy [6]. $\mathrm{P}$-gp is a protein product of $m d r l$ gene, located on the lumenclose side of Blood Brain Barrier (BBB) capillaries and on the podocytic process of astrocytes outside the blood capillaries [7]. This functions as an energy-dependent drug pump, protecting tissues from toxics and exogenous chemicals, and limiting fat-soluble substances into the brain [8]. Most antiepileptic drugs have a high liposolubility, and these are natural substrates of P-gp [9]. Therefore, P-gp may limit antiepileptic drugs from traveling through the $\mathrm{BBB}$, reducing their concentrations in the brain; leading to the drug-resistance of intractable epilepsy.

Calcium antagonists are the earliest discovered drugs that can reverse $m d r l$ gene overexpression, and the anti-epilepsy effect of the calcium antagonist has been confirmed in the experimental animal model of epilepsy and clinical studies $[10,11]$. In addition to inhibiting epileptic seizures, calcium antagonists can also reduce damage to neurons through expanding cerebral blood vessels, improving cerebral blood supply, and blocking cell hypoxia or a series of pathophysiological changes caused by excessive metabolisminducing calcium overload [12-14]. Verapamil [10,11], a wellstudied calcium antagonists, has a restricted clinical application due to its large consumption and cardiovascular side effects. Thus, diltiazem hydrochloride (DTZ, a calcium channel blocker that mainly inhibits L-shaped channels, with relatively mild side effects) was chosen for this study on the reverse effect on $m d r l a$ and $m d r l b$ expression in the hippocampus. 


\section{Materials and Methods}

\section{Establishment of the animal model and groupings}

Establishment of animal model: A total of 75 seven-day old male Wistar rats (provided by the Animal Center of Shandong University of PR China) were used in this study. The initial body weight of these rats ranged between 11.3-13.7 g. These rats were separately fed under a $12 \mathrm{~h}$ light/dark cycle at $22-25^{\circ} \mathrm{C}$ ambient temperature and $60 \%$ humidity, with enough food and water. The rats were randomly assigned into the Kainic Acid (KA) group $(n=39)$ and control group $(n=36)$. Rats in the KA group were intraperitoneally injected with KA (1 $\mathrm{mg} / \mathrm{kg}$, diluted with normal saline until a concentration of 0.5 $\mathrm{mg} / \mathrm{ml}$ was achieved); while rats in the control group were intraperitoneally injected with the same dose of Normal Saline (NS). Lado's epileptic seizure classification [15] in juvenile rats was adopted in this study: grade 0 , no seizure; grade 1 , mechanical chewing; grade 2, continuous nod; grade 3, unilateral forelimb clonus; grade 3.5, alternate forelimb clonus; grade 4, bilateral forelimb clonus, backward movement; grade 5, bilateral forelimb clonus, backwards movement, fall; grade 6. running, screaming; grade 7 , tonic seizures. Intraperitoneal injection was conducted under aseptic conditions, and rats were continuously observed for eight hours. In the KA group, 2-10 min after the injection of KA, rats gradually appeared to have seizures above grade 5; and then, progressed into an epileptic state. Six rats twitched to death; and $24 \mathrm{~h}$ after, another two rats died. In the control group, no rat had epileptic seizures and no death occurred.

Afterwards, eight-hour daily observation was performed, the presence of spontaneous seizures and deaths were observed on each rat, and the number of seizures was recorded. Two weeks later, surviving rats in the KA group gradually presented with non-irritable unilateral or bilateral forelimb clonus, and could or could not keep their position; that is, the rats had Spontaneous Recurrent Seizures (SRS). Hence, the epileptic juvenile rat models were successfully established.

Experimental grouping: The 31 surviving rats in the KA group were randomly divided into three subgroups: EP (Epilepsy untreated with antiepitic drugs, $n=10$ ) group, EP + LTG (epilepsy rats treated with lamotrigine $n=11$ ) group, and $\mathrm{EP}+\mathrm{LTG}+\mathrm{DTZ}$ (epilepsy treated with lamotrigine and DTZ, $\mathrm{n}=10$ ) group. In addition, 36 rats in the control group were randomly divided into three subgroups: NS $(n=12)$ group, NS + LTG $(n=12)$ group, and NS+LTG+DTZ $(n=12)$ group. One week after the occurrence of SRS, rats in the EP+LTG group were given daily LTG gavage of $20 \mathrm{mg} / \mathrm{kg}$ by intubation [16]; while rats in the EP+LTG+DTZ group were given daily DTZ gavage of $10 \mathrm{mg} / \mathrm{kg}[10,11]$ in addition to LTG (LTG and DTZ were prepared with $1 \%$ sodium cellulose solution into the suspension liquid with a concentration of $2 \mathrm{mg} / \mathrm{ml}$ ). At the sixth week of medication, rats in each group were decapitated, and their hippocampi were obtained and placed in a $-80^{\circ} \mathrm{C}$ refrigerator.

\section{Extraction of total RNA and RT-PCR}

Total RNA was extracted from hippocampus by Trizol methods. The concentration and quantity of total RNA were measured by determining the value of OD260/280. The mixture of total RNA $(2 \mu \mathrm{l})$, oligodT $(2 \mu \mathrm{l})$ and DEPC water $(12.4 \mu \mathrm{l})$ was centrifuged for $3 \sim 5 \mathrm{~s}$ before the paraffin oil was mixed. The mixture was incubated at $70^{\circ} \mathrm{C}$ for $5 \mathrm{~min}$ in the water bath. Then it was cooled to $4^{\circ} \mathrm{C}$ and shortly centrifuged. RNase inhibitor $(0.6 \mu \mathrm{l}, 40 \mathrm{u} / \mu \mathrm{l}), 5$ times of reaction buffer $(5$ $\mu \mathrm{l})$, dNTP $(2 \mu \mathrm{l}, 10 \mathrm{mmol} / \mathrm{L})$ and MMLV $(1 \mu \mathrm{l}, 200 \mathrm{u} / \mu \mathrm{l})$ were added to the mixture and incubated at $42^{\circ} \mathrm{C}$ for $60 \mathrm{~min}$ and at $70^{\circ} \mathrm{C}$ for $10 \mathrm{~min}$ in the water bath. The synthesized cDNA was stored at $-20^{\circ} \mathrm{C}$ in the refrigerator. $50 \mu \mathrm{l}$ of PCR contained $5 \mu \mathrm{l}$ of $10 \mathrm{X}$ buffer, $0.5 \mu \mathrm{l}$ of dNTP, $4 \mu \mathrm{l}$ of $\mathrm{MgCl}_{2}$ (mmol/1), $1 \mu \mathrm{l}$ of each forward and reverse primers, $1 \mu \mathrm{l}$ of TacE and $34.5 \mu \mathrm{l}$ of DEPC water. The sequences of the primers were shown in Table 1. The parameters for PCR included $5 \mathrm{~min}$ of initial denaturation at $95^{\circ} \mathrm{C}$ followed by 32 cycles of $95^{\circ} \mathrm{C}$ for $30 \mathrm{~s}$, $56^{\circ} \mathrm{C}$ for $30 \mathrm{~s}, 72^{\circ} \mathrm{C}$ for $25 \mathrm{~s}$ and a final extension at $72^{\circ} \mathrm{C}$ for 7 min. PCR products $(8 \mu \mathrm{l})$ were mixed with $2 \mu \mathrm{l}$ of bromophenol blue and loaded onto agarose gel containing 0.5 $\mu \mathrm{g} / \mathrm{ml}$ ethidium bromide for eletrophoresis. The size of PCR products for $m d r l a, m d r l b$ and $\beta$-actin genes was $351 \mathrm{bp}, 326$ bp and $317 \mathrm{bp}$, respectively. Relative expression of $m d r l a$ and $m d r 1 b$ genes was calculated using the following formula: relative expression=OD260 $(m d r 1)-O D 260(\beta$-actin $)$.

\section{Statistical methods}

Software (SPSS11.5) was used to compare the average classification of epilepsy in the epilepsy group and the relative expression of mdrla, mdrlb levels between each group by using variance analysis in factorial design. $\mathrm{P}<0.05$ was considered to be statistically different.

\section{Results}

\section{LTG or/and DTZ could reduce the epileptic grades in the EP group}

The epileptic grade was decreased in rats of the EP+LTG and $\mathrm{EP}+\mathrm{DTZ}$ groups, compared to rats in the EP group, respectively $(\mathrm{p}<0.001$, and $\mathrm{p}<0.001)$. Moreover, there was interaction between DTZ and LTG $(p<0.05)$. The epileptic grade in rats of the EP+LTG+DTZ was the lowest in the EP group (Table 2 and Figure 1).

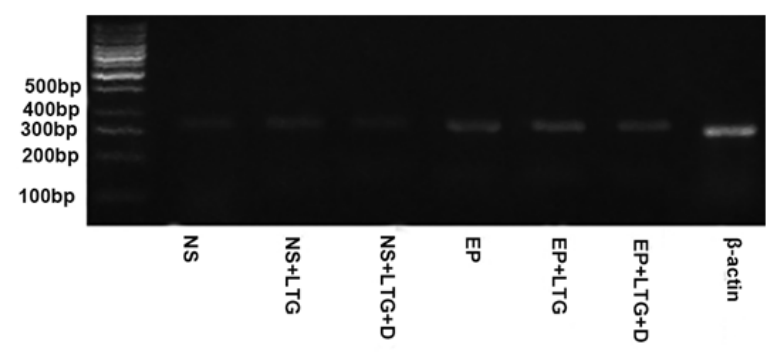

Figure 1. Examination of mdrla by RT-PCR. 
Application of diltiazem hydrochloride to hippocampus of juvenile rats with epilepsy and its effects on multidrugresistance gene expression

\section{Expression of mdr1a and mdr1b genes was increased in the EP group compared with the $\mathrm{NS}$ group}

Expression of mdrla and $m d r l b$ genes in the rats of the EP group was higher than that in the rats of the NS group $(p<0.001$, and $p<0.001)$ (Tables 3 and 4, Figures 1 and 2$)$.

\section{LTG alone had no effect on the expression of mdr1a and mdr1b genes}

Expression of $m d r l a$ and $m d r l b$ genes in the rats of NS+LTG group was not significantly different compared with that in the NS group ( $p>0.05$, and $p>0.05$ ) (Tables 3 and 4 , Figures 1 and 2). Meanwhile, there was no significant difference in the expression of $m d r l a$ and $m d r l b$ genes between the rats of EP + LTG group and EP group ( $>>0.05$, and $\mathrm{p}>0.05)$.

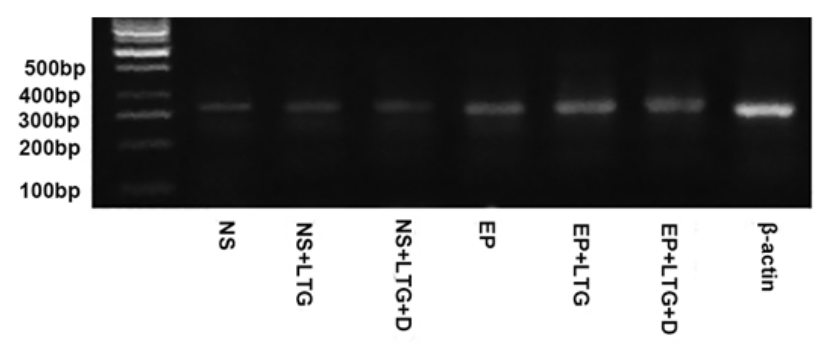

Figure 2. Examination of mdrlb by RT-PCR.

Table 1. Primer sequences for amplification of mdrla, mdrlb and $\beta$-actin genes.

\begin{tabular}{lllll}
\hline Gene & GenBank & Amplicon & Forward sequence & Reverse sequence \\
\hline$m d r 1 a$ & AF257746 & 351 & 5'-GATGGAATTGATAATGTGGACA-3' & 5'-AAGGATCAGGAACAATAAA- 3' \\
\hline$m d r 1 b$ & AY082609 & 326 & 5'-GAAATAATGCTTATGAATCCCAAAG-3' & 5'-GGTTTCATGGTCGTCGTCTCTTGA-3' \\
\hline$\beta$-actin & AF50872 & 317 & 5'-AAGATCCTGACCGAGCGTGG-3' & 5'-CAGCACTGTGTTGGCATAGAGG-3'
\end{tabular}

Table 2. Epilepsy grading in EP group.

\begin{tabular}{llllll}
\hline Source of variation & SS & DOF & MS & F value & P value \\
\hline LTG & 147.59 & 1 & 147.59 & 263.17 & $<0.0001$ \\
\hline D & 6.2 & 1 & 6.2 & 11.06 & 0.0024 \\
\hline LTG $\times$ D & 2 & 1 & 2 & 3.28 & 0.046 \\
\hline Error & 16.26 & 29 & 0.56 & & \\
\hline Sum & 172.06 & 32 & & & \\
\hline
\end{tabular}

\section{DTZ decreased the expression of mdr1a and mdr1b genes in the rats of the NS group and EP group}

Expression of $m d r l a$ and $m d r l b$ genes in the rats of NS+DTZ group was significantly lower than that in the rats of NS group $(p<0.001$, and $p<0.001)$ (Tables 3 and Table 4, Figures 1 and 2). And expression of $m d r l a$ and $m d r l b$ genes in the rats of EP + DTZ group was significantly lower than that in the rats of the EP group $(\mathrm{p}<0.001$, and $\mathrm{p}<0.001)$. There was no significant difference in the expression of $m d r l a$ and $m d r l b$ genes between the rats of NS+DTZ group and NS+LTG+DTZ group ( $>0.05$, and $p>0.05$ ). And the same result came from the EP + DTZ group and EP+LTG+DTZ group $(\mathrm{p}>0.05$, and $\mathrm{p}>0.05)$.

Table 3. Expression of mdrla gene in each group.

\begin{tabular}{llllll}
\hline Source of variation & SS & DOF & MS & F value & P value \\
\hline EP & 0.118814 & 1 & 0.118814 & 613.27 & $<0.0001$ \\
\hline LTG & $1.87 \mathrm{E}-05$ & 1 & $1.87 \mathrm{E}-05$ & 0.1 & 0.7573 \\
\hline D & 0.013991 & 1 & 0.013991 & 72.21 & $<0.0001$ \\
\hline LTG $\times$ D & $3.26 \mathrm{E}-06$ & 1 & $3.26 \mathrm{E}-06$ & 0.02 & 0.8973 \\
\hline
\end{tabular}

\begin{tabular}{llllll}
\hline EP $\times$ LTG & 0 & 1 & 0 & 0 & 0.9976 \\
\hline EP $\times$ D & 0.003988 & 1 & 0.003988 & 20.58 & $<0.0001$ \\
\hline EP $\times$ LTG $\times$ D & $1.1 \mathrm{E}-06$ & 1 & $1.1 \mathrm{E}-06$ & 0.01 & 0.9402 \\
\hline Error & 0.011043 & 57 & 0.000194 & & \\
\hline Sum & 0.146399 & 64 & & & \\
\hline
\end{tabular}

Table 4. Expression of mdrlb gene in each group.

\begin{tabular}{llllll}
\hline Source of variation & SS & DOF & MS & F value & P value \\
\hline EP & 0.03176 & 1 & 0.03176 & 40.04 & $<0.0001$ \\
\hline LTG & $4.17 \mathrm{E}-06$ & 1 & $4.17 \mathrm{E}-06$ & 0.01 & 0.9425 \\
\hline $\mathrm{D}$ & 0.015287 & 1 & 0.015287 & 19.27 & $<0.0001$ \\
\hline LTG $\times$ D & $1.41 \mathrm{E}-05$ & 1 & $1.41 \mathrm{E}-05$ & 0.02 & 0.8946 \\
\hline EP $\times$ LTG & 0.000016 & 1 & 0.000016 & 0.02 & 0.8876 \\
\hline EP $\times$ D & 0.010096 & 1 & 0.010096 & 12.73 & 0.0007 \\
\hline EP $\times$ LTG $\times$ D & $1.66 \mathrm{E}-06$ & 1 & $1.66 \mathrm{E}-06$ & 0 & 0.9637 \\
\hline Error & 0.045211 & 57 & 0.000793 & & \\
\hline Sum & 0.101621 & 64 & & &
\end{tabular}

\section{Discussion}

Epilepsy is a polygenic hereditary disease, characterized by high disability rate, long duration and frequent recurrence; which can cause a decline in a patient's learning and memory function $[1,2]$. Under serious conditions, it can even threat a patient's physical and mental health [15]. Epidemiological surveys have revealed that the incidence of epilepsy was 4.5-5.0/1000 [16], the incidence of epileptic state was $35 / 100,000$ [17], and approximately $25 \%$ of epilepsy patients 
are resistant to most anti-epileptic drugs and progress into intractable epilepsy [1]. Since 1981, hundreds of several kinds of substances have been found to reverse the expression of $m d r l$, which can be mainly divided into seven categories including calcium channel blockers, calmodulin antagonists, cyclosporine, protein kinase inhibitors, hormone and antihormonal compounds, isoquinoline alkaloids, and others such as vincristine and quinidine $[4,5]$. These substances can reverse the expression of $m d r l$ genes to a certain extent, and cut the amount of P-gp, in order to help drugs travel through the biological membrane into the cell body [6]. These substances not only have been widely discussed in studies on the drugresistance mechanism of tumors [12-14], but were found to have a potential value in promoting antiepileptic drugs into the brain $[10,11]$.

Drug therapy remains the main treatment for epilepsy. Therefore drugs that can reverse $m d r l$ expression and improve the antiepileptic drug concentrations in the brain may create a new way for the treatment of intractable epilepsy. In this study, juvenile rats were treated with KA and developed an epileptic state with spontaneous temporal lobe epilepsy; and these rat models were used as the objects of study, in order to investigate the reversal effect of calcium antagonist DTZ on $m d r l a$ and $m d r l b$ expression in the hippocampus. Temporal lobe epilepsy rat models caused by KA were treated with LTG combined with DTZ. After six weeks, it was found that $m d r 1$ expression levels in the hippocampus were lower in these rats than in rats treated with LTG alone; and the differences were statistically significant. This suggests that DTZ can reverse $m d r 1$ gene expression, and its reverse action is not associated with calcium channel blocking; but by competing the opportunity of binding with P-gp [18]. It realizes the reverse effect by acting as the competitive substrate of $m d r 1$ efflux pump, in order to increase the accumulation amount of therapeutic drugs in cells.

In our subsequent experiments, we will further evaluate the clinical value of DTZ from the experimental and clinical aspects; that is, whether its concomitant use with antiepileptic drugs can increase the concentration of the latter in the brain and improves the prognosis of epilepsy, and results in no serious adverse reactions.

\section{Ethic Statement}

This study complies with ethical standards.

\section{Disclosure}

There are no conflict interests to disclosure.

\section{References}

1. Regesta G, Tanganelli P. Clinical aspects and biological bases of drug-resistant epilepsies. Epilepsy Res 1999; 34: 109-122.

2. Volk HA, Potschka H, Locher W. Increased expression of the multidrug transporter P-glycoprotein in limbic brain regions after amygdala-kindled seizures in rats. Epilepsy Res 2004; 58: 67-69.

3. Lazarowski A, Ramos AJ, García-Rivello H, Brusco A, Girardi E. Neuronal and glial expression of the multidrug resistance gene product in an experimental epilepsy model. Cell Mol Neurobiol 2004; 24: 77-85.

4. Biedler JL. Genetic aspects of multidrug resistance. Cancer 1992; 70: 1799-1809.

5. Dombrowski SM, Desai SY, Marroni M, Cucullo L, Goodrich K, Bingaman W, Mayberg MR, Bengez L, Janigro D. Overexpression of multiple drug resistance genes in endothelial cells from patients with refractory epileps. Epilepsia 2001; 42: 1501-1506.

6. Lazarowski A, Czornyj L, Lubienieki F, Girardi E, Vazquez $\mathrm{S}$, DGiano C. ABC transporters during epilepsy and mechanisms underlying multidrug resistance in refractory epilepsy. Epilepsia 2007; 48: 140-149.

7. Lee G, Dallas S, Hong M, Bendayan R. Drug transporters in the central nervous system:brain barriers and brain parenchyma considerations. Pharmacol Rev 2001; 53: 569-596.

8. Schinkel AH. The physiological function of drugtransporting P-glycoprotein. Semin Cancer Biol 1997; 8: 161-170.

9. Rosado C, Cross SE, Pugh WJ, Roberts MS, Hadgraft J, Effect of vehicle pretreatment on the flux, retention, and diffusion of topically applied penetrants in vitro. Pharm Res 2003; 20: 1502-1507.

10. Summers MA, Moore JL, McAuley JW. Use of verapamil as a potential P- glycoprotein inhibitor in a patient with refractory epilepsy. Ann Pharmacother 2004; 38: 1631-1634.

11. Iannetti P, Spalice A, Parisi P. Calcium-channel blocker verapamil administration in prolonged and refractory status epilepticus. Epilepsia 2005; 46: 967-969.

12. Macdonald RL, Kelly KM. Antiepileptic drug mechanisms of action. Epilepsia 1995; 36: 2-12.

13. Yeung PK, Xu Z, Seeto D. Diltiazem reduces mortality and breakdown of ATP in red blood cell induced by isoproterenol in a freely moving rat model in vivo. Metabolites 2014; 4: 775-789.

14. Mokhtar Ibrahim M, Tawfique SA, Mahdy MM. Liposomal diltiazem $\mathrm{HCl}$ as ocular drug delivery system for glaucoma. Drug Dev Ind Pharm 2014; 40: 765-773.

15. Lado FA, Sperber EF, Moshe SL. Anticonvulsant efficacy of gabapentin on kindling in the immature brain. Epilepsia 2001; 42: 4458-4463.

16. Agarwal NB, Agarwal NK, Mediratta PK. Effect of lamotrigine, oxcarrbazepine and topiramate on cognitive functions and oxidative stress in PTZ-kindled mice. Seizure 2011; 20: 257-262.

17. Sadarangani M, Seaton C, Scott JA, Ogutu B, Edwards T, Prins A, Gatakaa H, Idro R, Berkley JA, Peshu N, Neville $\mathrm{BG}$, Newton CR. Incidence and outcome of convulsive status epilepticus in Kenyan children: a cohort study. Lancet Neurol 2008; 7: 145-150. 
Application of diltiazem hydrochloride to hippocampus of juvenile rats with epilepsy and its effects on multidrugresistance gene expression

Shudo N, Mizoguchi T, Kiyosue T. Two pyridine analogues with more effective ability to reverse multidrug resistance and with lower calcium channel blocking activity than their dihydropyridine counterparts. Cancer Res 1990; 50: 3055-3059.

\section{*Correspondence to}

Jun-Li Yang

Department of Pediatrics

Qilu Hospital

Shandong University

PR China 